\title{
Responsabilidade Social Empresarial: estudo sob a ótica do desempenho empresarial passado por meio da análise dos indicadores sociais e ambientais de uma empresa do setor de papel e celulose
}

\author{
Corporate Social Responsibility: \\ study from the point of view of past business performance through the analysis \\ of the social and environmental indicators of a pulp and paper company
}

Ademir Círico Junior ${ }^{1}$

Carlos Rafael Galvão ${ }^{2}$

${ }^{1}$ Mestre em Propriedade Intelectual e Transferência de Tecnologia para Inovação - Universidade Estadual do Centro-Oeste (UNICENTRO). Especialista em Tecnologias Educacionais e a Prática em Sala de Aula (INTERVALE). Especialista em Gestão, Contabilidade e Finanças Empresariais (INTERVALE). Graduado em Ciências Contábeis (UNICENTRO). CEO e Founder - NIX Contabilidade Online Ponta Grossa, Paraná, Brasil adeciricojr@gmail.com

${ }^{2}$ Graduando em Ciências Contabeis - Pontifícia Universidade Católica do Paraná - PUC-PR Diretor de Recursos Humanos - NIX Contabilidade Online Ponta Grossa, Paraná, Brasil carlosrafael.galv@gmail.com

\begin{abstract}
Resumo
O presente estudo visa responder a seguinte problemática: como elaborar um Balanço Social de uma empresa do setor de papel e celulose? Para tanto, a pesquisa possui como objetivo geral, elaborar o Balanço Social de uma empresa do setor de papel e celulose, utilizando o modelo do Instituto Brasileiro de Análises Sociais e Econômicas (IBASE). Quanto aos aspectos metodológicos, a pesquisa classifica-se, a priori, como pesquisa bibliográfica, por meio de livros, artigos, dissertações e teses sobre a temática em questão e, a posteriori, quantos aos meios, como pesquisa de campo, mediante a coleta de dados referente ao exercício 2016, em uma empresa da Região Centro-Sul do Paraná. Elenca-se que, para preservar o nome da entidade pesquisada, a empresa foi denominada como Verdes Campos. Preliminarmente, constatou-se que as ações da entidade estão direcionadas basicamente ao cumprimento das leis trabalhistas.
\end{abstract}

Palavras-chave: Responsabilidade Social Empresarial. Balanço social. Setor de papel e celulose.

\begin{abstract}
The present study aims to answer the following problems: how to prepare a Social Report of a company in the pulp and paper sector? For that, the research has as general objective, to prepare the Social Balance of a company of the pulp and paper sector, using the model of the Brazilian Institute of Social and Economic Analysis (IBASE). As for the methodological aspects, the research is classified, a priori, as a bibliographical research, through books, articles, dissertations and theses on the subject in question and, a posteriori, how many to the means, such as field research, through the collection data for the 2016 financial year, in a company in the Center-South Region of Paraná. It is estimated that, in order to preserve the name of the entity being surveyed, the company was denominated as Verdes Campos. Preliminarily, it was verified that the actions of the entity are directed basically to the fulfillment of the labor laws.
\end{abstract}

Keywords: Corporate Social Responsibility. Social balance sheet. Pulpand paper industry. 
1 Introdução

O interesse da sociedade pelo crescimento das empresas de forma sustentável está aumentando continuamente, tendo em vista a desigualdade social existente a nível local, nacional e internacional. De acordo com o Programa das Nações Unidas para o Desenvolvimento (PNUD, 2017) o Brasil dentro de uma população estimada em 206.081.432 habitantes, a incidência de pobreza atinge cerca de 9,96 \% da população nacional, ou seja, são mais de 20 milhões de brasileiros. Segundo a Associação Brasileira de Empresas de Pesquisa (ABEP, 2017), 26,6 \% da população brasileira (aproximadamente 54.817 .660 hab.) classifica- se pertencente às classes econômicas D-E, com renda média mensal familiar de $\mathrm{R} \$$ 639,78, ou seja, menor que o salário mínimo atual de $\mathrm{R} \$$ 937,00 .

Levando em consideração a realidade econômica da sociedade brasileira, percebe-se a disparidade da irresponsabilidade social no tocante a desigualdade social existente no país, visto que a sociedade necessita das benfeitorias governamentais, bem como, a contribuição por parte das empresas que possuem grande influência no mundo globalizado.

Dessa forma, a Responsabilidade Social Empresarial, mesmo sendo um tema recente, é um elemento de suma importância frente à realidade global, mediante a conscientização da população e das organizações rumo ao processo de desenvolvimento, por meio da preservação domeioambiente,bemcomoapromoçãodosdireitoshumanosconcomitantesàconstrução de uma sociedade economicamente justa, em favor da prosperidade social e ambiental (Reis e Medeiros,2007).

Na área contábil, a responsabilidade social e ambiental das entidades é discutida. O Conselho Federal de Contabilidade (CFC), por meio da Resolução no 1003/2004, ressalta sobre a importância dessa imprescindível responsabilidade das empresas. Além disso, esse Conselho aprovou a Norma Brasileira de Contabilidade Técnica (NBC T 15), cujo tema central diz respeito às informações de natureza social e ambiental, em que constam os procedimentos básicos para a elaboração de um demonstrativo com informações sociais e ambientais, sem, no entanto, estabelecer um modelo de relatório específico a ser elaborado pelas empresas.

Em meio a tantos problemas existentes no meio ambiente, mediante aos efeitos oriundos das ações prejudiciais causadas pela sociedade, há de acordo com Silva e Freire (2001), demanda por ações de caráter social e ambiental a serem executadas tanto por pessoas físicas, quanto por pessoas jurídicas, dentro e fora do ambiente organizacional.

Ferreira (2003) destaca que a empresa que causa danos ao meio ambiente, no mínimo, deve procurar agir de forma a reverter o dano, posteriormente evidenciando essas informações a respeito do desempenho ambiental da empresa, visando benefícios sociais e ambientais, priorizando, contudo, o objetivo principal da organização, que é agir de forma a evitar a degradação do meio ambiente.

A respeito das informações sociais e ambientais, de acordo com Ferreira (2003), no tocante a divulgação das atividades sociais e das contribuições ao meio ambiente por parte das empresas, verifica-se a necessidade de um modelo que possibilite estabelecer parâmetros de comparação e de qualidade. Partindo desse pressuposto, entende-se que a elaboração do Balanço Social gera benefícios recíprocos, ou seja, tanto para a empresa, quanto para o meio ambiente e para a sociedade, como um todo. 
Sobre os benefícios do Balanço Social para as empresas, de acordo com Costa (2012), o Balanço Social é um demonstrativo que torna público, as informações da empresa para a sociedade, e que justifica a sua existência por meio do custo-benefício, que, todavia, é positivo, por agregar à economia e à sociedade, por respeitar os direitos humanos dos seus colaboradores, e, "porque desenvolve todo o seu processo operacional sem agredir o meio ambiente" (Costa, 2012, p.175). Nesse sentido, verifica-se a real importância da elaboração e publicação do Balanço Social por parte das organizações, para evidenciar a Responsabilidade Socioambiental Empresarial com o meio ambiente e com a sociedade a qual estão inseridas.

Diante desse cenário, o trabalho visa responder a seguinte problemática: como elaborar um Balanço Social que demonstre as ações de Responsabilidade Social Empresarial de uma empresa do setor de papel e celulose?

Para tanto, o presente estudo possui como objetivo geral elaborar o Balanço Social de uma empresa do setor de papel e celulose, utilizando o modelo do Instituto Brasileiro de Análises Sociais e Econômicas (IBASE).

Ademais, este estudo centra-se na seguinte hipótese de pesquisa: ao longo do século XX, as empresas industriais iniciaram ações sociais e ambientais responsáveis, de modo a contribuírem para o desenvolvimento da sociedade e do meio ambiente.

\section{Referencial Teórico}

A estrutura teórica deste artigo refere-se à evolução da responsabilidade social no Brasil e no mundo e sua extensão no que tange as pessoas físicas e jurídicas.

\subsection{Responsabilidade Social}

A Responsabilidade Social é o conjunto de ações em prol dos benefícios paraa sociedade. São atitudes que visam o bem da coletividade social, para que haja um equilíbrio. Define-se também, no ambiente organizacional, como uma forma que pode conduzir os negócios das empresas de maneira a torná-las parceiras e, concomitantemente, corresponsáveis pelo desenvolvimento social (Ethos, 2016).

Para melhor compreensão sobre o tema em questão, faz-se necessário conceituar separadamente os termos: responsabilidade e social. Para Reis e Medeiros (2007) entende-se como responsabilidade a possibilidade de prever as consequências que as ações podem obter, corrigindo-as com base em tal previsão, antecipando, certamente, os resultados dessas ações, havendo a possibilidade de evitá-las.

Por outro lado, a expressão "social", refere-se à sociedade e a o que a ela pertence inerente as suas estruturas e condições, como exemplo, as questões sociais, as ações de natureza social, que, visam benefícios em favor da sociedade.

Tenório (2004) destaca que a responsabilidade social surge a partir do compromisso da organização com a sociedade, de modo geral, sendo que sua participação vai além da empregabilidade, geração de impostos e da lucratividade empresarial. O equilíbrio da empresa no que tange ao ecossistema social está associado à harmonia 
das ações empresariais com o equilíbrio ecológico, crescimento econômico e também com o desenvolvimento social, pilares do desenvolvimento sustentável.

Como se observa, a responsabilidade social está inserida diariamente no cenário empresarial, visto que para a empresa ser considerada socialmente responsável, é necessário que a entidade atue com responsabilidade e ética em todas as frentes, ultrapassando o foco de agir perante a sociedade e o meio ambiente apenas para obter status e, por conseguinte, lucro, mas sim, visando obter um equilíbrio frente ao desenvolvimento, tanto da sociedade, quanto do meio ambiente a qual estão inseridas mediante ações de natureza social e ambiental.

Outrossim, de acordo com Tinoco (2002) a visão socialmente responsável está sendo inserida gradativamente na sociedade, por meio da disseminação da conscientização em mídias eletrônicas, dentre elas: jornais, revistas, internet, entre outras ferramentas preponderantes para estaquestão.

O princípio das ações de caráter social está inserido, intrinsicamente, na consciência da sociedade em geral, de modo que haja benefícios em favor da sociedade. Segundo Costa (2012), é nas decisões individuais oriundas do cotidiano das pessoas que se fará presente, de certa forma, a responsabilidade social. Decisões no que diz respeito aos atospraticados diariamente pela sociedade, aos quais, estão presentes nas pequenas atitudes, como não jogar lixo na rua, não promover o desmatamento, ajudar pessoas com algum tipo de deficiência, ou seja, agir de alguma maneira em prol de benefícios tanto para a sociedade, quanto para o meio ambiente.

A Responsabilidade Social divide-se em cidadã, empresarial e ambiental. E uma das principais diferenças entre esses tipos de responsabilidade social é que a Responsabilidade Social Cidadã, segundo Melo Neto e Froes (2001), caracteriza-se como um estímulo em promover a cidadania, tanto coletiva, quanto individual.

De acordo com Karkotli e Aragão (2010), a Responsabilidade Social Empresarial, em sentido estrito, deve ser entendida como a obrigação que a organização possui em tornar-se agente de transformação social, destinando parte dos lucros auferidos no exercício para ações de natureza social e ambiental.

Barbieri e Cajazeira (2009) salientam que a Responsabilidade Social Empresarial e Ambiental envolve os dois tipos de responsabilidade citados, pois, tanto os cidadãos, como as empresas, necessitam agir de forma sustentável em prol do meio ambiente, pois, assim, evitarão catástrofes sociais e ambientais rumo ao desenvolvimento sustentável. Logo, se as empresas e a sociedade, em geral, agirem, concomitantemente, de forma sustentável, certamente haverá benefícios sociais e ambientais.

Portanto, analisa-se que, a Responsabilidade Social Empresarial envolve por parte das empresas ações de natureza social e ambiental, que visam benefícios coletivos, em prol do desenvolvimento da sociedade e do meio ambiente, visando um equilíbrio positivo entre ambas as partes.

\subsection{Responsabilidade social empresarial em nível global}

Em 1950, surgiram os primeiros estudos teóricos sobre a responsabilidade social das empresas, que foram desenvolvidos por meio de pressupostos conceituais da sociedade pós- industrial (Tinoco, 2002). No entanto, Tenório (2004) frisa que somente a partir da década de 70 que os trabalhos que foram desenvolvidos a respeito da temática, em questão, ganharam destaque e reconhecimento. A posteriori, surgiram às publicações dos resultados oriundos das pesquisas de autores da área, sobre o conceito e a aplicação da responsabilidade social das empresas. 
O debate referente à Responsabilidade Social Empresarial tem se tornado na atualidade onipresente, a nível nacional e internacional nos ambientes organizacionais e também nos órgãos internacional, e dentro dos movimentos da sociedade (pessoas naturais) e nas Instituições de Ensino Superior (IES) no que tange a pesquisas na citada área (Kleiton, 2004).

Todavia, observa-se que o tema em questão, é debatido diariamente, tanto no ambiente empresarial, como no acadêmico, com a finalidade de disseminar as questões inerentes às ações socialmente responsáveis, a serem praticadas por pessoas físicas e jurídicas. Portanto, faz-se necessário a análise dessas questões com relação à aplicabilidade de ações sociais e ambientais responsáveis no que tange ao cenárioorganizacional.

Tenório (2004) elenca que as questões relacionadas à responsabilidade social das empresas é um tema recente e possui polêmica, pois muitos empresários visam à estrita geração de lucros, isto é, focado somente nos resultados econômicos empresariais, contudo, a análise da responsabilidade social empresarial foi conduzida para o paradigma industrial.

Segundo Kleiton (2004), com o passar do tempo, houve a criação de umamplo entendimento sobre a Responsabilidade Social Empresarial sob a ótica de que, as empresas, enquanto atores sociais munidas de poderes econômicos e influências sociais, não devem apenas se autodisciplinarem, mas sim, colocarem-se formalmente a disposição do bem comum, de modo a evitarem e/ou reduzirem as falhas de funcionamento presentes no mercado.

Para Carrol (1979) a responsabilidade social das entidades consiste nas expectativas econômicas, éticas e legais que a sociedade possui relacionados às ações organizacionais de um determinado período. Assim, no presente contexto, as expectativas mencionadas que a sociedade possui, são oriundas das ações de natureza social, executadas pelas empresas, que visam benefícios em prol da coletividade.

Ashley (2002) destaca que a Responsabilidade Social Empresarial pode ser compreendida como o compromisso que as empresas possuem com a sociedade, oriundo das açõesrelacionadas à sociedade e o meio ambiente, direta ou indiretamente. Ademais, o citado autor refere-se às ações que a empresa deve realizar em favor de benefícios recíprocos, pró-ativamente, de modo a cumprir o seu papel específico com a sociedade, mediante a prestação de contas de forma transparente.

Tenório (2004) elenca que há dois tipos de Responsabilidade Social Empresarial presentes, a primeira diz respeito ao cumprimento da lei, das questões legais, e que, classifica- se como uma responsabilidade "exigida", ou seja, de forma compulsória. A outra responsabilidade, de acordo com Souza (2006) é a responsabilidade de caráter interno, sendo que, a empresa desenvolve determinada ação, quer seja, de cunho social e/ou ambiental, pelo fato de acreditar que essa ação é correta e necessita ser realizada. A organização usa os seus valores internos para subsidiar as suas decisões perante a empresa e a sociedade, em geral.

\subsection{Evolução da Responsabilidade Social Empresarial no Brasil}


De acordo com Tinoco (2002), foi a partir da década de 60 que a Responsabilidade Social das empresas tornou-se tema de discussão no Brasil por meio de uma carta publicada em 1965 pela Associação de Dirigentes Cristãos de Empresas do Brasil (ADCE Brasil) denominada como: "Carta de Princípios Cristãos", fato este preponderante para a utilização da expressão “Responsabilidade Social Empresarial” por empresas brasileiras.

Segundo Silva e Freire (2001), a ideia começou a ser difundida no país somente a partir dos anos 70, pois a conjuntura nacional presente neste período não era relativamente propícia para ideias que visassem transformações emudanças.

Contudo, foi a partir da década de 80 que o tema foi fortalecido no Brasil, pois, empresas começam a investir em ações de natureza social, mudando suas atitudes com relação à comunidade e o meio ambiente em prol de benefícios coletivos (Siqueira, 2009).

Além das efetivas ações sociais por parte das empresas, estas, a partir da década de 90 começaram a transparecer para a sociedade em geral, um perfil empresarial mais social e humano (Silva e Freire, 2001). Observa-se que, neste período houve o reconhecimento, por parte das empresas privadas, no que diz respeito as suas obrigações perante a sociedade e ao meio ambiente, oriundo de análises realizadas na época por lideranças do cenário empresarial brasileiro, ligadas aos desenvolvimentos do regime democrático do país, bem como as mobilizações da sociedade civil em busca de direitos de cidadania.

Alessio (2004) destaca que na década de 90 no Brasil, as empresas que lideravam se identificavam com os avanços da época, relacionados as mobilizações da sociedade civil, no tocante a reinvindicação de direitos de cidanania. Essas empresas perceberam a demanda por mudanças empresariais para o desenvolvimento social, assim, a partir da citada década, surgiram movimentos em prol da responsabilidade social das empresas, por meio do surgimento do Instituto Brasileiro de Análises Sociais e Econômicas (IBASE), o Instituto Ethos de Empresas e Responsabilidade Social e diversas ações institucionais voltadas ao desenvolvimento da sociedade e do meio ambiente.

Dessa forma, um dos principais fatores da evolução da Responsabilidade Social das empresas no Brasil desde os anos 90 até a atualidade, é, certamente, o surgimento de instituições centradas na finalidade de disseminar ideias sobre ações tanto de natureza social, como também ambiental, fortalecendo a visão socialmente responsável das empresas no país.

Morgan, Bergamini, \& Coda (1996) destacam que as organizações passaram por variadas visões perante a sociedade, dentre as quais, destaca-se as organizações vistas como um fluxo e transformação por meio das ações socialmente responsáveis que, beneficiam a sociedade e o meio ambiente, mediante práticas empresariais responsáveis.

Ademais, a preocupação das empresas no tocante as suas decisões tem-se caracterizado no decorrer deste período evolucional, como um elemento imprescindível para às empresas relacionando-se com a visão estratégica organizacional, em que a empresa reavalia os seus valores constantemente, levando em consideração o desenvolvimento sustentável. 


\subsubsection{A importância da Responsabilidade Social Empresarial}

Atualmente há um crescente aumento da complexidade dos negócios, no entanto, fato esse justificado pelos constantes avanços tecnológicos presentes no mercado que, por estar associado à produtividade, há o aumento da competitividade entre as empresas de diversos ramos, e, desta maneira, essas empresas tendem a investirem em ferramentas de gestão para obterem elementos diferenciais competitivos.

Por outro lado, segundo Ashley (2002), há disparidades e desigualdades sociais que estão aumentando diariamente, e que necessitam ser controladas pelas empresas em prol do desenvolvimento econômico, tanto social, quanto ambiental.

Para Bertoncello e Júnior (2007), há uma preocupação dos consumidores, que buscamno mercado, preferencialmente, produtos socialmente responsáveis que, todavia, tem chamadoa atenção dos gestores para desenvolverem produtos conforme a preferência dos seus clientes.

Alves (2001) relata que o número de fatores que influenciem diretamente na capacidade das empresas competirem no mercado a nível global tende a incluir a adesão a padrões de comportamento socialmente responsável. Contudo, esses padrões de comportamento estão sendo universalizados para suprir com as demandas presentes no mercado, tanto em nível nacional e internacional.

De acordo com Karkotli e Aragão (2010) as empresas mediante as ações empresariais, geram impacto para a sociedade e para o meio ambiente, seja, positivo ou negativo. Contudo, cabe à empresa buscar meios de fortalecer constantemente as suas relações tanto com os seus stakeholders, como também, com a sociedade e com o ambiente, em que, numa visão sistêmica, está inserida (Ferreira, 1997). Portanto, analisa-se que, as ações praticadas pelas organizações podem beneficiar ou prejudicar o meio ambiente e a sociedade na qual a empresa possui relações entre eles e estáinserida.

\subsubsection{Responsabilidade Social Empresarial Interna e Externa}

Siqueira (2009) destaca que no âmbito empresarial, observa-se que na atualidade, a responsabilidade das entidades, se comparado com o passado, possui uma amplitude maior, e está desenvolvendo- se progressivamente. Nos dias atuais, há demanda por ações socialmente responsáveis por parte das empresas, pois o mercado, de fato, exige uma consciência maior das entidades para estar atendendo a todos os seus stakeholders. Mediante a complexidade e o volume de informações a respeito, pode-se classificar a Responsabilidade Social Empresarial em: interna e externa.

Portanto, verifica-se a necessidade das organizações investirem em ações socialmente responsáveis em favor da coletividade, isto é, em prol do desenvolvimento da entidade, sociedade externa, meio ambiente e da economia.

No Quadro 1, são relatados as principais diferenças entre ambas classificações da Responsabilidade Social das empresas. 
Quadro 1 - Responsabilidade Social Interna e Externa

\begin{tabular}{|l|l|l|}
\hline \multicolumn{1}{|c|}{ Principais características } & \multicolumn{1}{|c|}{$\begin{array}{l}\text { Responsabilidade Social Interna } \\
\text { Área de atuação }\end{array}$} & $\begin{array}{l}\text { Responsabilidade Social Externa } \\
\text { empregados e seusdependentes. }\end{array}$ \\
\hline Foco & $\begin{array}{l}\text { Educação, salários, benefícios, } \\
\text { assistência médica, social e } \\
\text { odontológica. }\end{array}$ & $\begin{array}{l}\text { Educação, saúde, assistência social e } \\
\text { ecologia. }\end{array}$ \\
\hline Instrumentos & $\begin{array}{l}\text { Há o Programa de Recursos Humanos } \\
\text { e programas de previdência } \\
\text { complementar. }\end{array}$ & $\begin{array}{l}\text { Há as doações, programas de } \\
\text { voluntariado, parcerias e programas de } \\
\text { projetos sociais. }\end{array}$ \\
\hline Tipo de retorno & $\begin{array}{l}\text { Possui o retorno de produtividade, e, } \\
\text { contudo, o retorno para os } \\
\text { acionistas. }\end{array}$ & $\begin{array}{l}\text { Possui o retorno social, o retorno de } \\
\text { imagem, publicitário e para os acionistas. }\end{array}$ \\
\hline
\end{tabular}

Fonte: Adaptado de Melo Neto e Fróes (2001, p. 89).

Observa-se que, a partir desta diferenciação entre as formas de responsabilidade social da empresa, a Responsabilidade Social Empresarial interna são as ações socialmente responsáveis oriundas de dentro da organização, e a externa diz respeito ao campo fora dela, são as ações que visam benefícios para a sociedade e para o meio ambiente, ou seja, para as partes externas a empresa.

\section{Aspectosmetodológicos}

Segundo Silva (2003), a metodologia científica pode ser compreendida como o estudo referente à aplicação de um método em prol da busca de determinado conhecimento específico. Demo (2001) salienta que a metodologia de pesquisa além de ser considerada como um elemento de preocupação instrumental trata-se de formas de fazer ciência. A metodologia cuida dos caminhos, dos procedimentos e das ferramentas, visando sempre atingir os objetivos estabelecidos napesquisa, bem como, responder o problema de pesquisa.

Silva (2003) destaca que após haver a compreensão sobre a importância da metodologia científica, é possível identificarmos os métodos de pesquisa e observarmos que não existe apenas um método de pesquisa, pois há diversos métodos que visam atender às necessidades do pesquisador, de acordo com as finalidades da pesquisa, delimitados em objetivos: geral e específicos. A pesquisa associada a métodos científicos visa cultivar o espírito crítico, reflexivo, de forma a contribuir para o desenvolvimento da sociedade.

Para Oliveira (2003), a metodologia científica envolve o conhecimento como uma posse que as pessoas possuem no tocante a informação, que pode ser de uso imediato.

Assim, a metodologia é uma ferramenta que envolve benefícios tanto para a ciência, como para a sociedade, como um todo, por auxiliar as partes interessadas no processo de desenvolvimento do trabalho científico, dentre as formas existentes. 


\subsection{Caracterização da pesquisa}

Quanto à caracterização metodológica do presente estudo, relata-se no tocante a classificação metodológica da pesquisa, de acordo com os estudos desenvolvidos por Oliveira (2003), Gil (2010), Silva (2003) e Severino (2014). A priori, destaca-se que para a coleta de dados, utilizou-se o modelo do Balanço Social do IBASE, referente à versão de 2015 para analisar as ações de responsabilidade social empresarial da organização pesquisada.

Quanto à natureza da pesquisa, classifica-se como pesquisa aplicada, pois de acordo com Oliveira (2003), neste tipo de pesquisa, é definido as pesquisa que, no entanto, são voltadas à obtenção de conhecimentos com o foco em aplicá-los em uma área ou situação específica. Portanto, observa-se que o presente estudo classifica-se como pesquisa aplicada pelo fato de que a pesquisa foi direcionada para um estudo que envolveu a aplicação de um conhecimento em uma empresa, ou seja, situação e área específica.

Com relação à área de conhecimento, este estudo pertence às Ciências Sociais Aplicadas, que de acordo com Gil (2010), é uma área de conhecimento classificada segundo o Conselho Nacional de Desenvolvimento Científico e Tecnológico (CNPQ). O enquadramento desta classificação justifica-se, pois, tanto a graduação em Ciências Contábeis, quanto ao tema relacionado à organização pesquisada, em questão, pertencem às Ciências Sociais Aplicadas.

Quanto aos objetos de pesquisa, este estudo classifica-se como pesquisa descritiva, pois, segundo Severino (2014), esse tipo de pesquisa possui a finalidade de identificar e descrever variáveis, descrevendo as características do objeto pesquisado. Portanto, observa-se diante do contexto, que esse estudo caracteriza-se como pesquisa descritiva, pois foram levantados os dados de um determinado objeto de pesquisa, isto é, de todos os níveis hierárquicos da organização pesquisada, de modo a identificar e descrever as características específicas da população objeto deste estudo.

No tocante aos procedimentos técnicos para o desenvolvimento deste estudo, classifica-se, a priori, como pesquisa bibliográfica, pois foi realizado um levantamento teórico sobre a temática em questão, a partir de bases secundárias, por meio de livros, artigos científicos, monografias, dissertações e teses de modo a desenvolver um referencial teórico para relacionar aos dados coletados (Silva, 2003).

Este estudo também caracteriza-se como estudo de caso, visto que foi desenvolvido uma pesquisa, especificamente, em uma organização, de modo a identificar as ações organizacionais relacionadas a responsabilidade social empresarial, por meio de um estudo aprofundado, de modo a obter resultados detalhados (Severino, 2014).

Quanto aos meios, este estudo classifica-se como pesquisa de campo, pois foram realizadas visitas técnicas na empresa, objeto desta pesquisa, de modo a observar a estrutura setorial da organização, bem como, o processo produtivo e demais aspectos relevantes a serem observados com o foco em pontuá-los na pesquisa. A pesquisa de campo envolve um conjunto de fatores que estão relacionados, com a finalidade de analisar os dados coletados relacionando com as bibliográficas pesquisadas e destacadas no referencial teórico (Gil, 2010).

Ademais, destaca-se que para desenvolver o Balanço Social da Verdes Campos, foram coletadas informações internas quanto aos demonstrativos contábeis e relatórios gerenciais e de Recursos Humanos, 
especificamente, no tocante ao Balanço Patrimonial, Demonstração do Resultado do Exercício (DRE) e relatórios de gastos e investimentos e quanto ao quantitativo de Recursos Humanos referente ao exercício de 2016.

\section{Análise dos resultados}

Com a finalidade de verificar as ações de Responsabilidade Social Empresarial de uma empresa do setor de papel e celulose da região centro-sul do Paraná, a fim de alcançar, concomitantemente, os objetivos deste estudo, os dados foram coletados com base na estrutura do modelo de Balanço Social proposto pelo IBASE, na versão de 2015, ajustado a realidade da empresa pesquisada.

A escolha do modelo, a seguir apresentado, deu-se pelo fato de ser simples, de fácil entendimento e de melhor comparabilidade se comparado com outros modelos existentes. A estrutura do modelo de 2015 do Balanço Social da IBASE contempla Indicadores Econômicos, Indicadores Sociais Internos e Externos, Indicadores Ambientais, Indicadores do Corpo Funcional e Informações quanto ao exercício da cidadania empresarial com relação às ações que visam o desenvolvimento da economia, sociedade e do meio ambiente.

Ressalta-se que as informações aqui apresentadas e utilizadas para a elaboração do Balanço Social, bem como, da Demonstração do Valor Adicionado, foram fornecidas pela empresa.

\subsection{Indicadores do balançosocial}

Segundo Faur (2008) Karkotli e Aragão (2010) Costa (2012), o Balanço Social é composto por 7 categorias, sendo indicadores referentes ao comportamento da organização, demonstrada em indicadores: econômicos, sociais internos, sociais externos, ambientais, do corpo funcional, informações relevantes quanto ao exercício da cidadania empresarial e outras informações que a empresa reconheça como relevante a ser demonstrada no Balanço Social.

Costa (2012) define os Indicadores Econômicos como o conjunto de recursos empresariais para o desenvolvimento das atividades econômicas da empresa, esses recursos compreendem em Receita, oriundo das vendas de mercadorias e/ou prestação de serviços, e o total investido em mão-de-obra, que são recursos necessários para as operações empresariais.

Quanto aos Indicadores Sociais, estes indicadores dividem-se em Indicadores Sociais Internos e Externos. Contudo, observa-se que estes indicadores do modelo de Balanço Social da IBASE (2015) referem-se aos investimentos empresariais referentes ao corpo funcional da empresa (Indicadores Internos) e os investimentos relacionados à sociedade (Indicadores Externos), de modo que possa haver desenvolvimento coletivo.

Com relação aos Indicadores Ambientais, Faur (2008) destaca que estes indicadores evidenciam a forma responsabilidade da empresa, em matéria de ações que visem a preservação do meio ambiente, no que tange a ações empresariais associadas à redução do impacto ambiental.

Portanto, vale ressaltar que, com base nos indicadores apresentados no Balanço Social do modelo da IBASE, versão 2015, que foi ajustado a realidade da Verdes Campos, objeto deste estudo, é possível analisar as 
ações empresariais que visam contribuir para o desenvolvimento sustentável, ou seja, desenvolvimentos relacionados ao meio ambiente, economia e para a sociedade, de modo geral.

\subsubsection{Indicadores Econômicos}

A primeira parte do Balanço Social apresentado, refere-se aos indicadores econômicos da Verdes Campos do exercício de 2016, no que tange aos saldos da Receita Líquida (RL), Resultado operacional (RO) e da Folha de Pagamento Bruta (FPB), valores estes que compõem a Base de Cálculo do Balanço Social a ser apresentado, na sequência. Destaca-se que esses valores foram obtidos através de relatórios internos da empresa, quanto aos demonstrativos contábeis do exercício de 2016

Para fins de análise de balanço, de acordo com Ribeiro, Kian, Lopes, Cruz, \&Slomski,(2017), é necessário analisar os indicadores tendo como base, a Receita Líquida do exercício demonstrado com a finalidade de gerar dados percentuais comparáveis e com um elevado grau de confiabilidade.

Tabela 1 - Indicadores Econômicos

\section{Base de Cálculo}

Receita líquida $(\mathrm{RL})$

Resultado operacional (RO)

Folha de pagamento bruta (FPB)

Fonte: Dados da pesquisa (2017)

Conforme a Tabela 1, observa-se que a receita líquida da Verdes Campos em 2016 é de R\$ 350.240.258,96, seu resultado operacional é de $\mathrm{R} \$ 48.929 .851,94$, o que corresponde a 13,97\% da receita líquida, e sua folha de pagamento bruta é de $\mathrm{R} \$ 29.954 .252,45$ o que representa cerca de 8,55\% da receita líquida e $61,22 \%$ do resultado operacional. Portanto, observa-se que os resultados destes indicadores representam a luz da Responsabilidade Social Empresarial à participação relevante da entidade no que tange as obrigações trabalhistas, no entanto faz-se necessário analisar os indicadores seguintes para melhor entendimento sobre as ações socialmente responsáveis da entidade que foram executadas no exercício demonstrado (Tinoco,2002).

\subsubsection{Indicadores Sociais Internos}

O segundo campo da estrutura do Balanço Social representa as ações sociais da organização com relação à parte interna da empresa, isto é, aos investimentos voluntários e obrigatórios que a Verdes Campos realizou no exercício de 2016 aos seus colaboradores (as), tais como os investimentos relacionados à alimentação, saúde, cultura, capacitação e desenvolvimento profissional. Destaca-se que os dados foram coletados por meio da Demonstração do Resultado do Exercício (DRE) e de relatórios de gastos e investimentos efetuados em 2016 pela Verdes Campos. 
Tabela 2 - Indicadores SociaisInternos

\begin{tabular}{|l|l|}
\hline \multicolumn{1}{|c|}{ Indicadores Sociais Internos } & \multicolumn{1}{c|}{\begin{tabular}{c} 
Valor (R\$) \\
\hline Alimentação
\end{tabular}} \\
\hline Encargossociaiscompulsórios & $962.225,79$ \\
\hline Previdênciaprivada & $8.681 .161,05$ \\
\hline Saúde & $162.879,08$ \\
\hline Segurança e saúde no trabalho & $1.198 .023,35$ \\
\hline Educação & $268.283,78$ \\
\hline Cultura & $151.557,11$ \\
\hline Capacitação e desenvolvimento profissional & $2.031,23$ \\
\hline Crechesouauxílio-creche & $184.105,06$ \\
\hline Participação nos lucros ou resultados & 00,00 \\
\hline Outros & $8.736,67$ \\
\hline Total - Indicadores sociais internos & 00,00 \\
\hline
\end{tabular}

Fonte: Dados da pesquisa (2017).

Verifica-se que os gastos com alimentação que a Verdes Campos possuiu no exercício demonstrado totalizaram-se o valor de $\mathrm{R} \$ 962.225,79$, o que corresponde a $0,27 \%$ da receita líquida e 1,97\% do resultado operacional da entidade em 2016. Estes gastos referem-se ao vale alimentação dos colaboradores, visto que a empresa possui um número elevadode pessoal, conforme evidenciado na sequência nos Indicadores do CorpoFuncional.

Observa-se com base na Tabela 2, que os principais investimentos da Verdes Campos no que tange aos Indicadores Sociais Internos em 2016 foram os encargos sociais compulsórios, correspondente ao INSS, FGTS, SAT, salário educação, SESI, SENAI e SEBRAE que, contudo, totalizaram no valor de R\$ 8.681.161,05. O salário educação equivale a uma porcentagem fixa de $2,5 \%$ sobre a folha de pagamento dos colaboradores da empresa.

No item Segurança e Saúde no Trabalho a Verdes Campos investiu R\$ 268.283,78, neste valor estão inclusos gastos com a Comissão Interna de Prevenção de Acidentes (CIPA) e com equipamentos de segurança como: luvas, capacetes, cinto de segurança, óculos de proteção, extintores dentre outros itens necessários para a segurança dos colaboradores da empresa, isto é, para a prevenção contra todos os aspectos negativos que podem afetar a segurança e a saúde do corpo funcional daentidade.

A empresa realizou em 2016 um investimento de R\$ 151.557,11 em educação, referentes a auxílios em cursos técnicos e de pós-graduação, incentivando os colaboradores a buscarem desenvolvimento profissional mediante cursos especializados voltados a melhorias no tocante ao exercício das vossas profissões.

Os investimentos em cultura totalizaram apenas $\mathrm{R} \$ \mathbf{2 . 0 3 1 , 2 3}$ correspondente a menos de um por cento da receita líquida $(0,0006 \%)$ e do resultado operacional $(0,0042 \%)$, por tanto, pelo fato de que o percentual 
realizado é relativamente ínfimo, optou-se em não demonstrar a porcentagem deste investimento nos Indicadores Sociais Internos da estrutura do Balanço Social da Verdes Campos no exercício de 2016.

Concomitante aos investimentos em educação, a Verdes Campos investiu R\$1 184.105,06 em capacitação e desenvolvimento profissional, sendo que esses gastos referem-se a treinamentos diversos, nas áreas de formação técnica, segurança, treinamentos obrigatórios, comportamentais, entre outros, para haver benefícios recíprocos, tanto para os colaboradores, quanto para a empresa.

A empresa não realiza investimentos relacionados à creche ou auxílio-creche, bem como, não foi evidenciado outros investimentos além dos quais foram demonstrados na estrutura dos indicadores sociais internos.

A participação nos lucros ou resultados foi de apenas R\$ 8.736,67, pois em 2016 não foram atingidas as metas do fator gerador coletivo anual que foram estabelecidas pela Verdes Campos.

\subsubsection{Indicadores SociaisExternos}

Esse campo refere-se às ações socialmente responsáveis que a Verdes Campos realizou frente à parte externa da organização, ou seja, no tocante aos investimentos realizados em benefícios a sociedade em geral.

Tabela 3 - Indicadores Sociais Externos

\begin{tabular}{|c|c|}
\hline Indicadores Sociais Externos & $\begin{array}{c}2016 \\
\text { Valor (R\$) }\end{array}$ \\
\hline Educação & 00,00 \\
\hline Cultura & 00,00 \\
\hline Saúde e saneamento & 00,00 \\
\hline Esporte & $42.000,00$ \\
\hline Combate à fome e segurança alimentar & 00,00 \\
\hline Outros & 00,00 \\
\hline Total das contribuições para a sociedade & $42.000,00$ \\
\hline Tributos (excluídos encargos sociais) & $98.554 .572,77$ \\
\hline Total - Indicadores sociais externos & $98.596 .572,77$ \\
\hline
\end{tabular}

Fonte: Dados da pesquisa (2017).

A Verdes Campos investiu em 2016 apenas no quesito esporte no valor de $R \$ 42.000,00$, correspondente a $0,01 \%$ da receita líquida e $0,09 \%$ do resultado operacional, mediante o patrocínio do clube de futebol do município de Guarapuava no Estado do Paraná. 
Elenca-se que os pagamentos dos tributos evidenciados nos indicadores sociais externos da Verdes Campos em 2016, são atos compulsórios, isto é, exigidos por lei e não são realizados de forma voluntária pela empresa.

\subsubsection{Indicadores Ambientais}

Neste campo do Balanço Social, é evidenciado os investimentos que a Verdes Campos realizou em 2016 com a finalidade de minimizar seus impactos ambientais, tendo em vista a contribuição com a preservação do meio ambiente, visto que a empresa atua na área de papel e celulose.

Tabela 4 - Indicadores Ambientais

Indicadores Ambientais

\begin{tabular}{ll} 
Investimentos relacionados com a produção/ operação da empresa & 00,00 \\
\hline Investimentos em programas e/ou projetos externos & 00,00 \\
Total dos investimentos em meio ambiente & 00,00
\end{tabular}

2016

Valor (R\$)

Valor (RS)
0,00

0,00

Quanto ao estabelecimento de "metas anuais" para minimizar resíduos, o consumo( ) não possui metas em geral na produção/ operação e aumentar a eficácia na utilização de recursos( ) cumpre de 51 a $75 \%$ ( ) naturais, a empresa. cumpre de 0 a $50 \%$

(x) cumpre de 76 a $100 \%$

Fonte: Dados da pesquisa (2017).

Os resultados obtidos quanto aos Indicadores Ambientais da Verdes Campos significam a luz da Responsabilidade Social Empresarial de acordo com Tenório (2004) que a empresa não possui responsabilidade ambiental de forma plena, visto que os investimentos são parciais, com relação a melhoria dos processos internos da organização, isto é, as ações executadas limitam-se a investimentos para aempresa.

\subsubsection{Indicadores do Corpo Funcional}

Este item evidencia a relação que a empresa possui com seu público interno, ou seja, com os colaboradores da entidade, por meio de investimentos em prol do desenvolvimento dos colaboradores. Através destes indicadores, é possível verificar o quantitativo dos Recursos Humanos da empresa estudada, quanto ao percentual de distribuição quanto ao gênero, idade e demais fatores. 
Tabela 5 - Indicadores do Corpo Funcional

\begin{tabular}{|c|c|}
\hline d. l. & 2016 \\
\hline № de empregados (as) ao final do período & 442 \\
\hline № de admissões durante o período & 112 \\
\hline № de empregados (as) terceirizados (as) & 45 \\
\hline № de estagiários (as) & 12 \\
\hline № de empregados (as) acima de 45 anos & 82 \\
\hline № de mulheres que trabalham na empresa & 79 \\
\hline$\%$ de cargos de chefia ocupados por mulheres & $0,00 \%$ \\
\hline № de negros (as) que trabalham na empresa & 3 \\
\hline$\%$ de cargos de chefia ocupados por negros (as) & $0,00 \%$ \\
\hline № de pessoas com deficiência ou necessidades especiais & 15 \\
\hline
\end{tabular}

Fonte: Dados da pesquisa (2017).

Observa-se, conforme a Tabela 5, que o total de colaboradores (as) ao final do período de 2016 era composto de 442 de pessoal. Contudo, elenca-se para o fato de que, desta totalidade, 45 são terceirados (as), correspondendo a aproximadamente $10 \%$ do total do corpo funcional do exercício demonstrado.

Dos 442 colaboradores, 79 são do gênero feminino, ou seja, 17,87\% do total, e 363 são do gênero masculino, o que corresponde a $82,13 \%$. Portanto, observa-se que o gênero masculino prevalece no tocante a totalidade do corpo funcional da Verdes Campos. A empresa possuía 12 estagiários (as) estagiando na área administrativa ao final do exercício findo. Dos 442 colaboradores, 82 eram de idade acima de 45 anos, cerca de $18,55 \%$ do corpo funcional.

Entretanto, fato que se considera relevante e injustificável é a desproporcionalidade no tocante ao total do corpo funcional do gênero feminino, comparativamente ao gênero masculino. Portanto, verifica-se que a desigualdade de gênero na entidade pesquisada faz-se presente, mediante os dados coletados.

Para melhor observação e compreensão do quadro sobre o corpo funcional da Verdes Campos em 2016, foi desenvolvido um quadro com os dados apresentados acima, em porcentagem. 
Tabela 6 - Relação do número de colaboradores (as) da Verdes Campos

\begin{tabular}{|c|c|c|}
\hline \multirow{2}{*}{\multicolumn{2}{|c|}{$\begin{array}{l}\text { VERDES CAMPOS } \\
\text { Relação do número de colaboradores (as) }\end{array}$}} & \multirow{3}{*}{$\begin{array}{l}\% \\
100 \%\end{array}$} \\
\hline & & \\
\hline № de empregados (as) ao final do período & 442 & \\
\hline № de empregados (as) terceirizados (as) & 45 & $10,18 \%$ \\
\hline № de estagiários (as) & 12 & $2,71 \%$ \\
\hline № de empregados (as) acima de 45 anos & 82 & $18,55 \%$ \\
\hline № de homens que trabalham na empresa & 363 & $82,13 \%$ \\
\hline № de mulheres que trabalham na empresa & 79 & $17,87 \%$ \\
\hline № de negros (as) que trabalham na empresa & 3 & $0,68 \%$ \\
\hline № de pessoas com deficiência ou necessidades especiais & 15 & $3,39 \%$ \\
\hline
\end{tabular}

Fonte: Dados da pesquisa (2017).

De acordo com o art. 93 da Lei no 8.213/91, as costas para os portadores de necessidades especiais é matéria legal e a empresa deve cumprir respeitando os seguintes critérios:

Art. 93. A empresa com 100 (cem) ou mais empregados está obrigada a preencher de $2 \%$ (dois por cento) a $5 \%$ (cinco por cento) dos seus cargos com beneficiários reabilitados ou pessoas portadoras de deficiência, habilitadas, na seguinte proporção: I - até 200empregados. $.2 \%$;

II-de201a500. $3 \%$

III-de501a1.000. $4 \%$

IV-de1.001emdiante $.5 \%$.

$\S 1^{\circ}$ A dispensa de pessoa com deficiência ou de beneficiário reabilitado da Previdência Social ao final de contrato por prazo determinado de mais de 90 (noventa) dias e a dispensa imotivada em contrato por prazo indeterminado somente poderão ocorrer após a contratação de outro trabalhador com deficiência ou beneficiário reabilitado da Previdência Social.

$\S 2^{\circ}$ Ao Ministério do Trabalho e Emprego incumbe estabelecer a sistemática de fiscalização, bem como gerar dados e estatísticas sobre o total de empregados e as vagas preenchidas por pessoas com deficiência e por beneficiários reabilitados da Previdência Social, fornecendo-os, quando solicitados, aos sindicatos, às entidades representativas dos empregados ou aos cidadãos interessados.

Observa-se, portanto, que a Verdes Campos, por possuir 442 colaboradores deveria ter 13 colaboradores portadores de deficiência ou necessidades especiais, ou seja, 3\% do seu quadro funcional. Para tanto, a empresa está dentro da normalidade obrigatória, pois em 2016 a entidade possuía 15 colaboradores nas condições mencionadas, correspondente a 3,39\% do total.

\subsubsection{Informações Relevantes quanto ao Exercício da Cidadania Empresarial}


Observa-se que as empresas socialmente responsáveis possuem informações relevantes no tocante ao exercício da cidadania empresarial, com relação aos benefícios a comunidade interna a entidade (colaboradores (as), gestores (as)), bem como, as partes externas da entidade.

Tabela 7 - Informações relevantes quanto ao exercício da cidadania empresarial

\begin{tabular}{|c|c|c|c|}
\hline Informações relevantes quanto ao exercício da cidadania empresarial & \multicolumn{3}{|c|}{2016} \\
\hline Relação entre a maior e a menor remuneração na empresa & \multicolumn{3}{|l|}{$18.000,00$} \\
\hline Número total de acidentes de trabalho & \multicolumn{3}{|l|}{53} \\
\hline $\begin{array}{l}\text { Os projetos sociais e ambientais desenvolvidos pela empresa foram } \\
\text { definidos por: }\end{array}$ & ( ) direção & ) direção e gerências & ( ) todosempregados \\
\hline $\begin{array}{l}\text { Os padrões de segurança e salubridade no ambiente de trabalho foram } \\
\text { definidos por: }\end{array}$ & $\begin{array}{l}\text { ) direção e } \\
\text { gerências }\end{array}$ & ( ) todosempregados & $\begin{array}{l}\text { ( ) todos } \\
+ \text { Cipa }\end{array}$ \\
\hline $\begin{array}{l}\text { Quanto à liberdade sindical, ao direito de negociação coletiva e à } \\
\text { representação interna dos (as) trabalhadores (as), a empresa: }\end{array}$ & ( ) não se envolve & ( $X$ ) segue as normas da OIT & ) incentiva e segue a OIT \\
\hline A previdênciaprivadacontempla: & ( ) direção & direção e gerências & ( $X$ ) todosempregados \\
\hline A participaçãocontempla: dos lucros ou resultados & ( ) direção & direção e gerências & ( $\mathrm{X}$ ) todosempregados \\
\hline $\begin{array}{l}\text { Na seleção dos fornecedores, os mesmos padrões éticos e de } \\
\text { responsabilidade social e ambiental adotados pela empresa: }\end{array}$ & $\begin{array}{l}(x) \\
\text { nãosãoconsiderados }\end{array}$ & () sãosugeridos & ( ) sãoexigidos \\
\hline $\begin{array}{l}\text { Quanto à participação de empregados (as) em programas de trabalho } \\
\text { voluntário, a empresa: }\end{array}$ & ( ) não se envolve & (X) apoia & Jrganiza e incentiva \\
\hline Número total de reclamações e críticas de consumidores (as): & na empresa 157 & no Procon & naJustiça \\
\hline \% de reclamações e críticas atendidas ou solucionadas: & na empresa $100 \%$ & $\begin{array}{l}\text { noProcon } \\
\%\end{array}$ & $\begin{array}{l}\text { naJustiça } \\
\%\end{array}$ \\
\hline \multicolumn{4}{|l|}{ Valor adicionado total a distribuir (em mil $\mathrm{R} \$$ ): } \\
\hline \multirow{5}{*}{ Distribuição do Valor Adicionado (DVA): } & \multicolumn{3}{|l|}{$60 \%$ governo } \\
\hline & \multicolumn{3}{|c|}{$18 \%$ colaboradores (as) } \\
\hline & \multicolumn{3}{|l|}{ _\%acionistas } \\
\hline & \multicolumn{3}{|l|}{$24 \%$ terceiros } \\
\hline & \multicolumn{3}{|l|}{$-2 \%$ retido } \\
\hline
\end{tabular}

Fonte: Dados da pesquisa (2017). 
Observa-se na Tabela 7, que a relação entre o maior e a menor contraprestação remuneratória na empresa equivale a $\mathrm{R} \$ 18.000,00$ sendo este um valor relativamente alto.

O número de acidentes de trabalho é considerado médio-alto, foram 53 acidentes de trabalho em 2016, uma média de aproximadamente 4 acidentes por mês. De acordo com o gestor da Verdes Campos, as causas dos acidentes, em sua totalidade, referem-se ao comportamento inseguro por parte dos colaboradores (as).

Quanto aos projetos sociais e ambientais, bem como, os padrões de segurança e salubridade no trabalho desenvolvido pela empresa foram todos definidos pela direção e gerências. A empresa apoia os seus colaboradores (as) no tocante a participação em programas de trabalho voluntário, como projetos sociais, em prol dacoletividade.

Quanto ao total de 157 reclamações e críticas de consumidores (as) na empresa, considera-se um número alto e relevante, entretanto, a Verdes Campos possui como meta, reduzir para 95 reclamações anuais em 2017.

Em 2016, o total do valor adicionado a distribuir foi de $\mathrm{R} \$ 167.480 .370,00$ sendo que deste montante, $60 \%$ foi destinado ao governo, $18 \%$ aos colaboradores (as), $24 \%$ a terceiros, - $2 \%$ relativo a lucros retidos. Portanto, observa-se quanto a distribuição da riqueza da Verdes Campos, que o montante de maior relevância destinado em 2016 foi para o governo, no tocante ao cumprimento de fins compulsórios, como exemplo, os encargos sociais, dentre eles o INSS, FGTS, SAT, Salário educação, SESI, SENAI, SEBRAE.

Diante desse cenário, verifica-se que as ações da empresa limitam-se ao o que é estritamente obrigatório, para atender a contabilidade fiscal em nível nacional. Elenca-se que para fins de elaboração do Balanço Social da Verdes Campos, bem como, das outras empresas pertencentes ao Grupo Verdes Campos, foi necessário elaborar a Demonstração do Valor Adicionado do exercício de 2016, de forma concomitante para a evidenciação da porcentagem do valor adicionado a distribuir de cada parte interessada.

\subsubsection{Outras Informações}

Neste item são apresentados os dados que a empresa reconheça como relevantes para o melhor entendimento dos usuários (internos e externos) no que tange as práticas socialmente responsáveis realizadas pela entidade.

5 Considerações finais

A Verdes Campos, empresa pesquisada, objeto deste estudo, é uma indústria, e a partir da coleta de dados, observa-se que a hipótese de pesquisa não pode ser confirmada, visto que por mais que há indústrias conscientizadas a respeito das ações sociais e ambientais, em prol do desenvolvimento sustentável (economia, meio ambiente e sociedade), este estudo revelou que os resultados apresentados com base no desenvolvimento do Balanço Social da Verdes Campos, objeto deste estudo, centrou-se apenas nas ações que visam atender as obrigações trabalhistas. 
Quanto aos Indicadores Sociais Internos, sugere-se que a Verdes Campos invista mais em programas com a finalidade de beneficiar os seus colaboradores principalmente na área de cultura/lazer e participações nos lucros ou resultados. Ademais, faz-se necessário que a empresa busque outras formas de investimentos para contribuir com o desenvolvimento do corpo funcional, motivando-os concomitantemente.

Em relação aos Indicadores Sociais Externos, sugere-se o apoio da empresa a atividades desenvolvidas em benefício da comunidade, como auxílio à educação, saúde e saneamento, cultura e no combate à fome e o desenvolvimento da segurança alimentar. No que tange aos Indicadores Ambientais, recomenda-se a criação de um programa de conscientização ambiental, por parte da entidade, visando estabelecer metas para minimizar os danos causados ao meio ambiente.

No tocante ao corpo funcional, sugere-se uma maior divulgação das vagas existentes para portadores de deficiências físicas, e também, buscar aumentar vagas para colaboradoras do gênero feminino, para haver um equilíbrio na empresa, bem como, promover o corpo funcional do gênero feminino em cargos de chefia, evidenciando a importância da igualdade de gênero no ambiente organizacional.

Quanto ao quesito cidadania empresarial, recomenda-se que à organização desenvolva um programa para a redução de acidentes de trabalho, concomitante ao aumento da fiscalização em áreas de risco, visto que a principal causa dos acidentes de trabalho na Verdes Campos é o comportamento inseguro dos colaboradores (as). Sugere-se a participação de todos os colaboradores (as) em decisões no tocante as definições dos projetos sociais e ambientais, buscando motivá-los mediante a inclusão do corpo funcional em decisões que visem à contribuição do meio ambiente e da sociedade, em geral.

Portanto, conclui-se que, é necessário, para além da empresa estar ciente sobre a importância da Responsabilidade Social Empresarial, faz-se imprescindível que a entidade haja de forma a contribuir com a sociedade e com o meio ambiente por meio de incentivos em prol da coletividade. Contudo, para que a entidade torne-se socialmente responsável, a mesma necessita investir e interagir ainda mais nas questões ambientais e sociais.

Destaca-se que os objetivos deste estudo foram alcançados, no tocante elaboração do Balanço Social de uma empresa do setor de papel e celulose, utilizando o modelo do IBASE, com o foco em identificar as ações de responsabilidade social empresarial da organização, objeto deste estudo. Assim, frisa-se a relevância deste estudo, como elemento de contribuição para as empresas e para o meio ambiente e a sociedade, em geral, visto que o Balanço Social é uma ferramenta que contribui para a visibilidade empresarial, por meio da transparência das organizações no tocante as boas práticas de responsabilidade social e ambiental por parte das empresas. Assim, destaca-se a importância das empresas buscarem ser cada vez mais social e ambientalmente responsáveis rumo ao desenvolvimento sustentável (economia, meio ambiente e sociedade).

Por fim, sugere-se a continuidade de pesquisas futuras sobre a temática em questão, no que tange a elaboração e comparação do Balanço Social por meio do desempenho empresarial de organizações tanto do setor de papel e celulose, como dos demais setores empresariais existentes, a fim de verificar as ações de Responsabilidade Social Empresarial das organizações. 
Referências

Alessio, R. (2004). Responsabilidade social das empresas no Brasil: reprodução de postura ou novos rumos? Porto Alegre: Edipucrs.

Alves, L. E. S. (2001). Governança e cidadania empresarial. Revista de Administração de Empresas, v. 41, n. 4, p. 78-86.

Ashley, P. A. (2002). Ética e responsabilidade social nos negócios. São Paulo: Saraiva.

Barbieri, J. C.,\&Cajazeira. J. E. R. (2009). Responsabilidade social empresarial e empresa sustentável: da teoria à prática. São Paulo: Saraiva.

Associação Brasileira de Empresas de Pesquisa. Critérios Brasil. Recuperado em 25 maio, 2017, de http://www.abep.org/.

Bertoncello, S. L. T., \& Chang JR, J. (2007). A importância da responsabilidade social corporativa como fator de diferenciação. FACOM-Revista da Faculdade de comunicação da FAAP, n. 17, p. 70-76.

Carrol, A. B. (1979). A three-dimensional conceptual model of corporate performance. Academicof Management Review. v. 4, n. 4, p. 497-505.

Conselho Federalde Contabilidade (CFC). (2016). Resolução no 1003, de 06 desetembro de 2004, NBCT 15. Dispõe sobre as informações de natureza social e ambiental. Recuperado em 01 julho, 2016, dewww.cfc.org.br.

Costa, C. A. G. (2012). Contabilidade ambiental: mensuração, evidenciação e transparência. São Paulo: Atlas.

Demo, P. (2001). Saber pensar. 2. ed. São Paulo: Cortez.

Ethos, Instituto. Recuperado em 16 setembro, 2016, de www3.ethos.org.br.

Faur, A. R., Machado, V. S., Fernandes, L. P., Monteiro, P. R. A., \& Ferreira, A. C. D. S. (2008). Balanço social relatório de desempenho social? Análise dos setores petroquímico e elétrico no Rio de Janeiro. Pensar Contábil, v. 6, n. 25.

Ferreira, A. A., Pereira, M. I., \& Reis, A. C. F. (1997). Gestão empresarial: de Taylor aos nossos dias. São Paulo: Pioneira.

Ferreira, A. C. S. (2003). Contabilidade ambiental: uma informação para o desenvolvimento sustentável. São Paulo: Atlas.

Gil, A. C. (2010). Como elaborar projetos de pesquisa. São Paulo: Atlas.

Instituto Brasileiro de Análises Sociais e Econômicas (IBASE). (2016). Balançosocial. Recuperado em 10 outubro, 2016, dewww.ibase.br/pt/prestando-contas/balanco-social.

Karkotli, G.,\&Aragão, S. D. (2010). Responsabilidade social: uma contribuição à gestão transformadora das organizações. Rio de Janeiro: Vozes.

Kleiton, M. P. (2004). A ética nas relações entre empresas e sociedade: fundamentos teóricos da responsabilidade social empresarial. In: Encontroanual da Anpad, v. 28. p. 1-13.

Lei n. 8.213, de 24 de Julho de 1991. Dispõe sobre os planos de benefícios da previdência social. Recuperado em 17 setembro, 2017, de http://www.planalto.gov.br/ccivil_03/leis/L8213compilado.htm.

Morgan, G., Bergamini, C. W., \& Coda, R. (1996).Imagens da organização. São Paulo: Atlas.

Neto, M. F.,\&Froes, C. (2001).Responsabilidade Social \& Cidadania Empresarial: a administração do terceiro setor, Qualitymark.

Oliveira, A. B. S. (2003). Métodos e técnicas de pesquisa em contabilidade. São Paulo: Saraiva.

Programa das Nações Unidas para o Desenvolvimento. Sobreo Brasil: estatísticas do Brasil. Recuperado em 25 maio, 2018, de http://www.br.undp.org/content/brazil/pt/home/countryinfo.html.

Reis, C. N., \& Medeiros, L. E. (2007). Responsabilidade Social das Empresas e Balanço Social.São Paulo: Atlas.

Ribeiro, C. A., Kian, C., Lopes, J. F. P., Cruz, C. V. O. A., \&Slomski, V. (2017). Práticas contábeis adotadas por entidades do terceiro setor: análise empírica junto às empresas prestadoras de serviços contábeis de Londrina. Revista de Estudos Contábeis, 6(11), 81-100.

Severino, A. J. (2014).Metodologia do trabalho científico. São Paulo: Cortez.

Silva, A. C. R. (2003). Metodologia da pesquisa aplicada à contabilidade: orientações de estudos, projetos, artigos, relatórios, monografias, dissertações, teses. São Paulo: Atlas.

Silva, C. A. T., \& Freire, F, S. (2001) Balanço social: teoria e prática. São Paulo: Atlas.

Siqueira, J. R. M. (2009). Balanço social: evidenciação da responsabilidade social. In: Contabilidade ambiental e relatórios sociais. Ferreira, A. C. S.; Siqueira, J. R. M.; Gomes, M.

Z. (Org). São Paulo: Atlas.

Souza, A. C. C. (2006). Responsabilidade social e desenvolvimento sustentável: a incorporação dos conceitos à estratégia empresarial. 230 p. Dissertação. Mestrado em Ciências em Planejamento Energético. Universidade Federal do Rio de Janeiro (UFRJ), Rio de Janeiro. 
Tenório, F. G. (2004). Responsabilidade social empresarial: teoria e prática. Rio de Janeiro: Editora FGV.

Tinoco, J. E. P. (2002). Balanço Social: balanço da transparência corporativa e da concertação social. Revista Brasileira de Contabilidade, n. 135, p. 56.

Recebido em: 19 jun. 2018 / Aprovado em: 18 mar. 2019

\section{Para referenciar este texto}

Cirico, A. Jr., \& Galvão, C. R. (2020). Responsabilidade Social Empresarial: estudo sob a ótica do desempenho empresarial passado por meio da análise dos indicadores sociais e ambientais de uma empresa do setor de papel e celulose. Exacta, 18(2), 334-354. https://doi.org/10.5585/ExactaEP.v18n2.8820. 